\title{
LETTER
}

\section{Impact of sepsis-associated cytokine storm on plasma NGAL during acute kidney injury in a model of polymicrobial sepsis}

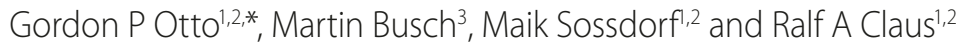

Acute kidney injury (AKI) is a common, early and severe organ dysfunction during sepsis [1]. One promising biomarker for its early detection is neutrophil gelatinaseassociated lipocalin (NGAL) [2,3]. During sepsis, cytokines, including TNFa, IL6 and IL10, initiate a broad variety of signalling that affect AKI development. Using a lipopolysaccharide-induced AKI animal model, correlation of NGAL expression to TNF $\alpha$ but not IL6 expression was previously described [4]. During polymicrobial sepsis, it remains unclear whether there is a correlation between protein levels and the role of plasma NGAL as an inflammatory protein rather than a marker of AKI.

After gaining permission (Thueringer Landesamt fuer Lebensmittelsicherheit und Verbraucherschutz; TVA02-10/10), sepsis in mice was induced by injection of human faeces. Mice were sacrificed at baseline, $6 \mathrm{~h}$ and 24 h post-sepsis insult. Plasma NGAL, cytokines, blood urea nitrogen (BUN), serum creatinine (Crea) and other laboratory markers were ascertained and ANOVA and Spearman correlation testing performed.

Sepsis symptoms developed within the first $6 \mathrm{~h}$ (Table 1). During sepsis, IL6, IL10, monocyte chemotactic protein-1 (MCP1), interferon-gamma (IFN $\gamma$ ) and TNF $\alpha$ significantly increased (Figure 1a). Concerning sepsisassociated AKI, plasma NGAL was already elevated at 6 h, whereas Crea and BUN remained stable (Figure 1b). After $24 \mathrm{~h}$, these markers were increased as well. Although Crea was still normal at $6 \mathrm{~h}$, there was a significant positive correlation with NGAL, which was maintained at $24 \mathrm{~h}$ (Table 2). A significant correlation between NGAL and TNF $\alpha$ was observed at $6 \mathrm{~h}$ and $24 \mathrm{~h}$. In addition, significant correlations of NGAL with IL6, IL10 and MCP1 were found exclusively after $24 \mathrm{~h}$ but not after $6 \mathrm{~h}$. No correlation was detected for IFNy.

Data indicate that the early increase of plasma NGAL during sepsis is not solely a result of inflammation and its associated cytokine storm but rather results from early kidney damage. As described recently [4], the association of TNF $\alpha$ with NGAL could be confirmed during polymicrobial sepsis. Since cytokines stimulate the expression of each other, it might be assumed that the late association of NGAL with IL6, IL10 and MCP1 was triggered by TNFo. We hypothesize that septic AKI, as remote organ failure, is mainly initiated by TNF $\alpha$. This might

Table 1. Characteristics of healthy and polymicrobial infected mice

\begin{tabular}{|c|c|c|c|c|}
\hline Sepsis characteristics & Healthy & $6 \mathrm{~h}$ sepsis & 24 h sepsis & $P$-value \\
\hline $\mathrm{WBC}\left(\times 10^{3} / \mu \mathrm{l}\right)$ & $5.45(4.58-5.9)$ & $1.85(1.7-2.18)^{* * *}$ & $0.7(0.6-1.23)^{* * *}$ & $<0.0001$ \\
\hline Platelet count $\left(\times 10^{3} / \mu \mathrm{l}\right)$ & $1,238(1,205-1,339)$ & $1,002(844-1,100)^{* * *}$ & $470(399.8-603.5)^{* * *}$ & $<0.0001$ \\
\hline $\mathrm{LDH}(\mathrm{U} / \mathrm{l})$ & $335(296-375.5)$ & $462(388-585)^{* *}$ & $545.5(456.3-671.3)^{* * *}$ & $<0.0001$ \\
\hline ASAT (U/I) & $41.5(38-47.5)$ & $77.5(64.25-108.3)^{* * *}$ & $123.5(96.25-157)^{* * *}$ & $<0.0001$ \\
\hline $\operatorname{ALAT}(\mathrm{U} / \mathrm{I})$ & $20.5(19-22.75)$ & $32.5(26.25-45)^{* *}$ & $33.5(24.25-46.25)^{* *}$ & $<0.001$ \\
\hline Bacterial burden kidneys (CFU) & & $0(0-275)$ & $7,650(575-24,350)$ & $<0.0001$ \\
\hline Bacterial burden blood (CFU) & & $15(0-65)$ & $20,800(1,050-68,900)$ & $<0.001$ \\
\hline
\end{tabular}

Data are presented as median \pm interquartile range. Investigated clinical chemistries from plasma samples of healthy controls ( $\mathrm{n}=16$ to 20 ) and of polymicrobial infected mice $6 \mathrm{~h}(\mathrm{n}=16$ to 20$)$ and $24 \mathrm{~h}(\mathrm{n}=16$ to 20 ) post-sepsis induction as well as bacterial burden from whole blood (6 and $24 \mathrm{~h}$; $\mathrm{n}=24)$. Statistically significant difference compared with healthy controls by ANOVA: ${ }^{*} P \leq 0.01,{ }^{* * *} P \leq 0.001$. ALAT, alanine aminotransferase; ASAT, aspartate aminotransferase; CFU, colony forming units; LDH, lactate dehydrogenase; WBC, white blood cells. 
(a)
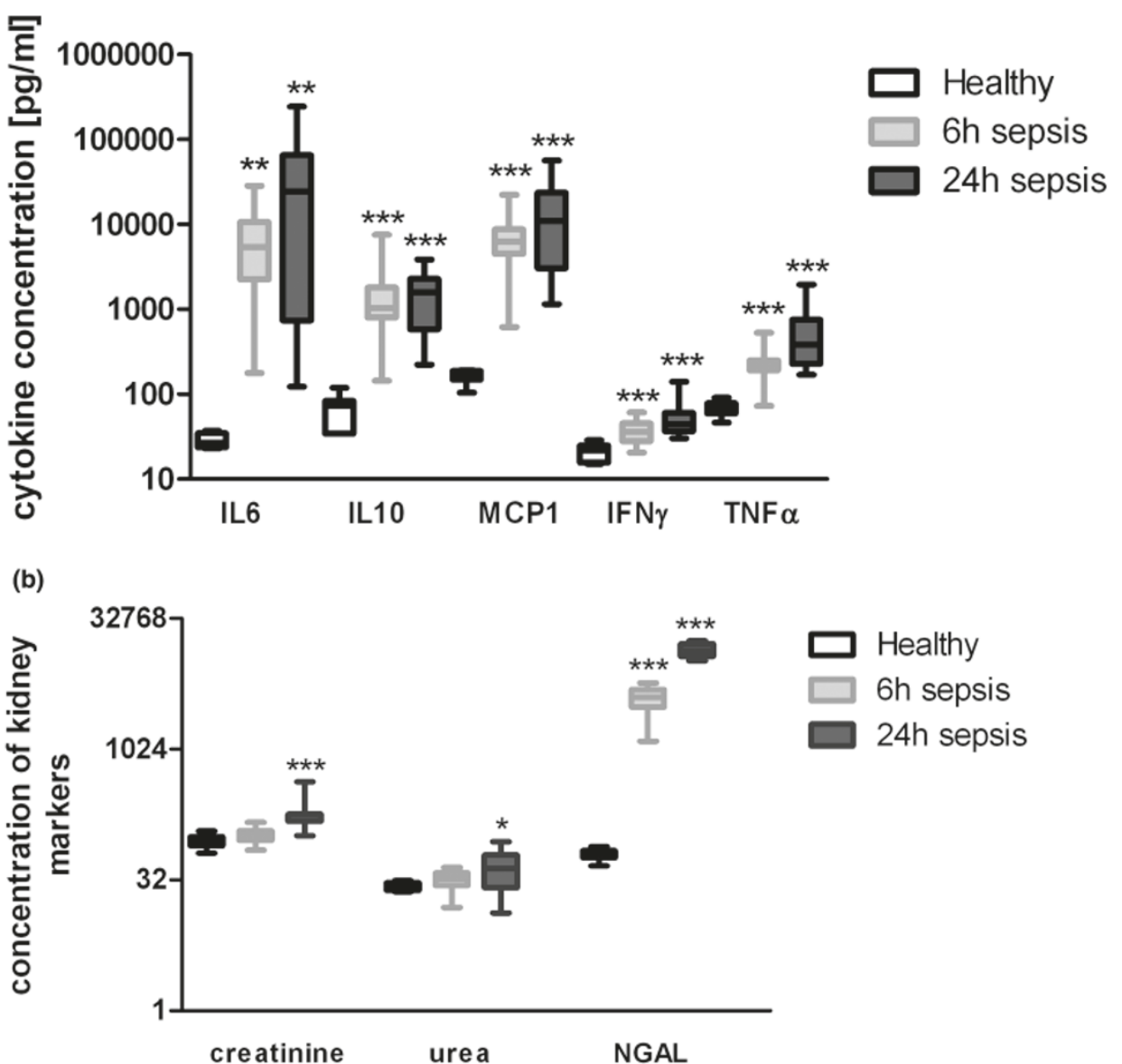

Figure 1. Laboratory findings during polymicrobial sepsis in mice. (a) Concentration of IL6, IL10, monocyte chemotactic protein-1 (MCP1), interferon-gamma (IFNY) and TNFa in healthy untreated mice as well as 6 and $24 \mathrm{~h}$ after sepsis induction. (b) Concentration of creatinine ( $\mu \mathrm{g} / \mathrm{dl})$, blood urea nitrogen (urea; $\mathrm{mg} / \mathrm{dl}$ ) and neutrophil gelatinase-associated lipocalin (NGAL; $\mathrm{ng} / \mathrm{ml}$ ) in healthy, untreated mice as well as 6 and $24 \mathrm{~h}$ after sepsis induction. ${ }^{*} P<0.05,{ }^{*} P<0.01,{ }^{* *} P<0.001$, all compared to healthy untreated mice.

Table 2. Correlation of NGAL and creatinine with various cytokines

\begin{tabular}{|c|c|c|c|c|c|c|c|c|}
\hline & \multicolumn{4}{|c|}{ NGAL } & \multicolumn{4}{|c|}{ Crea } \\
\hline & \multicolumn{2}{|c|}{$6 \mathrm{~h}$ sepsis } & \multicolumn{2}{|c|}{$24 \mathrm{~h}$ sepsis } & \multicolumn{2}{|c|}{$6 \mathrm{~h}$ sepsis } & \multicolumn{2}{|c|}{$24 \mathrm{~h}$ sepsis } \\
\hline & $r$ & $P$-value & $r$ & $P$-value & $r$ & $P$-value & $r$ & $P$-value \\
\hline $\begin{array}{l}\text { Crea resp. } \\
\text { NGAL }\end{array}$ & 0.48 & $<0.05$ & 0.78 & $<0.001$ & 0.48 & $<0.05$ & 0.78 & $<0.001$ \\
\hline IL6 & -0.05 & 0.853 & 0.68 & $<0.01$ & 0.38 & 0.095 & 0.73 & $<0.001$ \\
\hline IL10 & 0.23 & 0.351 & 0.76 & $<0.001$ & 0.38 & 0.103 & 0.77 & $<0.001$ \\
\hline MCP1 & 0.36 & 0.127 & 0.74 & $<0.001$ & 0.42 & 0.066 & 0.69 & $<0.01$ \\
\hline IFNY & 0.25 & 0.293 & 0.22 & 0.383 & 0.37 & 0.114 & 0.03 & 0.909 \\
\hline TNFa & 0.60 & $<0.01$ & 0.70 & $<0.01$ & 0.39 & 0.09 & 0.69 & $<0.01$ \\
\hline
\end{tabular}

Spearman correlation analyses correlating plasma neutrophil gelatinase-associated lipocalin (NGAL) and creatinine (Crea) with various cytokines, all measured from samples of polymicrobial infected mice $6 \mathrm{~h}(\mathrm{n}=20)$ and $24 \mathrm{~h}(\mathrm{n}=18)$ post-sepsis induction. $P$-values are given. IFNy, interferon-gamma; IL, interleukin; MCP1, monocyte chemotactic protein-1; TNF, tumour necrosis factor. 
explain further why higher NGAL levels are found in septic versus non-septic AKI [5].

\section{Abbreviations}

AKI, acute kidney injury; BUN, blood urea nitrogen; Crea, creatinine; IFN, interferon; IL, interleukin; MCP1, monocyte chemotactic protein-1; NGAL neutrophil gelatinase-associated lipocalin; TNF, tumour necrosis factor.

\section{Competing interests}

All authors declare that they have no competing interests.

\section{Authors' contributions}

GPO and MB designed the study and wrote the first draft of the manuscript. MS was involved in data analysis and interpretation. RAC was involved in supervision, and data analysis and its interpretation. All authors read and approved the final draft of the manuscript.

\section{Acknowledgements}

The authors would like to thank Edith Walter and Danny Himsel for their excellent technical support. This publication was supported by the BMBF to the Center of Sepsis Control and Care (BMBF; FKZ 01EO1002, CSCC; project number D1.21 and A1.2).

\section{Author details}

'Center for Sepsis Control and Care (CSCC), Jena University Hospital, Erlanger Allee 101, 07747 Jena, Germany. ${ }^{2}$ Department of Anesthesiology and Intensive Care, Jena University Hospital, Erlanger Allee 101, 07747 Jena, Germany. ${ }^{3}$ Clinic for Internal Medicine (KIM III) - Nephrology, Jena University Hospital, Erlanger Allee 101, 07747 Jena, Germany.
Published: 19 March 2013

\section{References}

1. Chertow GM, Burdick E, Honour M, Bonventre JV, Bates DW: Acute kidney injury, mortality, length of stay, and costs in hospitalized patients. J Am SoC Nephrol 2005, 16:3365-3370.

2. Clerico A, Galli C, Fortunato A, Ronco C: Neutrophil gelatinase-associated lipocalin (NGAL) as biomarker of acute kidney injury: a review of the laboratory characteristics and clinical evidences. Clin Chem Lab Med 2012, 50:1505-1517.

3. Constantin JM, Futier E, Perbet S, Roszyk L, Lautrette A, Gillart T, Guerin R, Jabaudon M, Souweine B, Bazin JE, Sapin V: Plasma neutrophil gelatinaseassociated lipocalin is an early marker of acute kidney injury in adult critically ill patients: a prospective study. J Crit Care 2010, 25:176 e171-176.

4. Han M, Li Y, Liu M, Cong B: Renal neutrophil gelatinase associated lipocalin expression in lipopolysaccharide-induced acute kidney injury in the rat. BMC Nephrol 2012, 13:25.

5. Bagshaw SM, Bennett M, Haase M, Haase-Fielitz A, Egi M, Morimatsu H, D'Amico G, Goldsmith D, Devarajan P, Bellomo R: Plasma and urine neutrophil gelatinase-associated lipocalin in septic versus non-septic acute kidney injury in critical illness. Intensive Care Med 2010, 36:452-461.

doi:10.1186/cc12540

Cite this article as: Otto GP, et al:: Impact of sepsis-associated cytokine storm on plasma NGAL during acute kidney injury in a model of polymicrobial sepsis. Critical Care 2013, 17:419. 